\title{
The Yin and Yang of Calcium Effects on Synaptic Vesicle Endocytosis
}

\author{
Xin-Sheng Wu and Ling-Gang Wu \\ National Institute of Neurological Disorders and Stroke, Bethesda, Maryland 20892
}

\begin{abstract}
A large number of studies suggest that calcium triggers and accelerates vesicle endocytosis at many synapses and non-neuronal secretory cells. However, many studies show that prolonging the duration of the stimulation train, which induces more calcium influx, slows down endocytosis; and several studies suggest that instead of triggering endocytosis, calcium actually inhibits endocytosis. Here we addressed this apparent conflict at a large nerve terminal, the calyx of Held in rat brainstem, in which recent studies suggest that transient calcium increase up to tens of micromolar concentration at the micro/nano domain triggers endocytosis. By dialyzing $0-1 \mu \mathrm{M}$ calcium into the calyx via a whole-cell pipette, we found that slow endocytosis was inhibited by calcium dialysis in a concentration-dependent manner. Thus, prolonged, small, and global calcium increase inhibits endocytosis, whereas transient and large calcium increase at the micro/nano domain triggers endocytosis and facilitates endocytosis. This yin and yang effect of calcium may reconcile apparent conflicts regarding whether calcium accelerates or inhibits endocytosis. Whether endocytosis is fast or slow depends on the net outcome between the yin and yang effect of calcium.
\end{abstract}

Key words: calcium; endocytosis

\section{Introduction}

Exocytosis releases neurotransmitters to mediate synaptic transmission, whereas endocytosis recycles exocytosed vesicles to maintain synaptic transmission. Accumulated studies show that buffering calcium with EGTA or reducing the extracellular calcium concentration slows down endocytosis at many synapses and endocrine cells, suggesting that calcium speeds up endocytosis (Ceccarelli and Hurlbut, 1980; Artalejo et al., 1995; Henkel and Betz, 1995; Cousin and Robinson, 1998; Marks and McMahon, 1998; Moser and Beutner, 2000; Neves et al., 2001; Sankaranarayanan and Ryan, 2001; Wu et al., 2005; Balaji et al., 2008). Recent studies at calyces and hippocampal synapses show that calcium may speed up slow, rapid, and bulk endocytosis by tens of folds, suggesting that calcium triggers endocytosis (Hosoi et al., 2009; Wu et al., 2009; Sun et al., 2010). Consequently, how calcium triggers endocytosis has been actively studied (Sun et al., 2010; Yamashita et al., 2010; J. Yao et al., 2011; Yao and Sakaba, 2012; L.H. Yao et al., 2012).

In contrast to the above conclusion, prolonging the stimulation train, which increases calcium influx, prolongs endocytosis at many preparations, such as goldfish ribbon-type synapses (von Gersdorff and Matthews, 1994), frog neuromuscular junctions (Wu and Betz, 1996), hippocampal synapses (Sankaranarayanan

Received Aug. 21, 2013; revised Jan. 6, 2014; accepted Jan. 10, 2014.

Author contributions: X.-S.W. and L.-G.W. designed research; X.-S.W. performed research; X.-S.W. analyzed data; L.-G.W. wrote the paper.

This work was supported by the National Institute of Neurological Disorders and Stroke Intramural Research Program. We thank Drs. Fujun Luo, Jiansong Sheng, and Zhen Zhang for critical reading of this manuscript.

Correspondence should be addressed to Ling-Gang Wu, National Institute of Neurological Disorders and Stroke,

35 Convent Drive, Building 35, Room 2B-1012, Bethesda, MD 20892. E-mail: wul@ninds.nih.gov.

DOI:10.1523/JNEUROSCI.3582-13.2014

Copyright $\odot 2014$ the authors $\quad 0270-6474 / 14 / 342652-08 \$ 15.00 / 0$ and Ryan, 2000; Balaji et al., 2008; Sun et al., 2010), calyces (Sun et al., 2002; Wu et al., 2005; Yamashita et al., 2005; Renden and von Gersdorff, 2007), and chromaffin cells (Artalejo et al., 1995; Elhamdani et al., 2006). A pioneering study two decades ago shows that increasing the intracellular calcium concentration at goldfish ribbon-type synapses inhibits endocytosis, suggesting that calcium inhibits endocytosis (von Gersdorff and Matthews, 1994). A study of single-vesicle endocytosis at hippocampal synapses suggests that calcium inhibits endocytosis (Leitz and Kavalali, 2011). A recent study at hippocampal synapses shows that calcium speeds up endocytosis in the first few action potentials, but slows down endocytosis as action potentials continue (Armbruster et al., 2013).

Apparently, how calcium regulates endocytosis is rather controversial. We attempted to resolve this controversy at the calyx of Held nerve terminal, where studies suggest that large, transient calcium influx at $>10 \mu \mathrm{M}$ at the calcium micro/nano domain triggers slow endocytosis (Hosoi et al., 2009; Wu et al., 2009; Yamashita et al., 2010). This suggestion is based on three observations: (1) reducing calcium influx during brief depolarization by reducing the extracellular calcium concentration or the voltage driving force abolishes slow endocytosis (Wu et al., 2009); (2) the fast calcium buffer BAPTA (1-10 mM), but not the slow buffer EGTA, abolishes slow endocytosis induced by brief depolarization, suggesting that the transient calcium micro/nano domain triggers endocytosis (Hosoi et al., 2009; Wu et al., 2009; Yamashita et al., 2010); and (3) >10 $\mu \mathrm{M}$ calcium is needed to induce slow endocytosis (Hosoi et al., 2009). Here we determined whether endocytosis is inhibited by prolonged, global, but small calcium increase to $\sim 0.5-1 \mu \mathrm{M}$, which has been observed in seconds to minutes after repetitive stimulation at nerve terminals (Kamiya and Zucker, 1994; von Gersdorff and Matthews, 1994; 
A
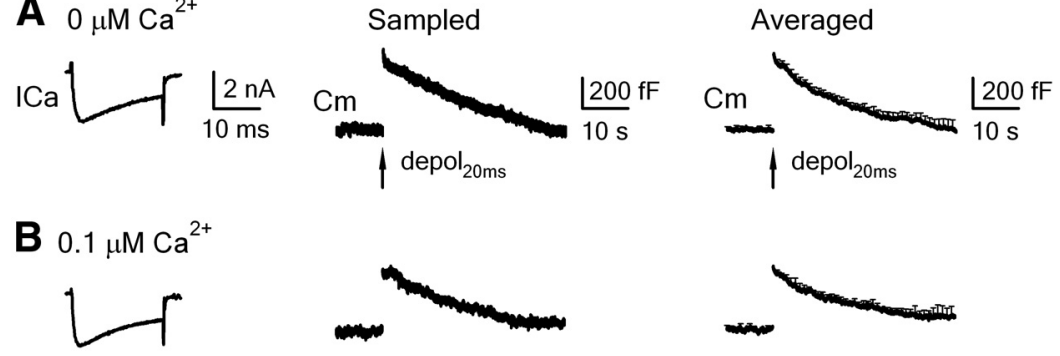

C $0.2 \mu \mathrm{M} \mathrm{Ca}^{2+}$
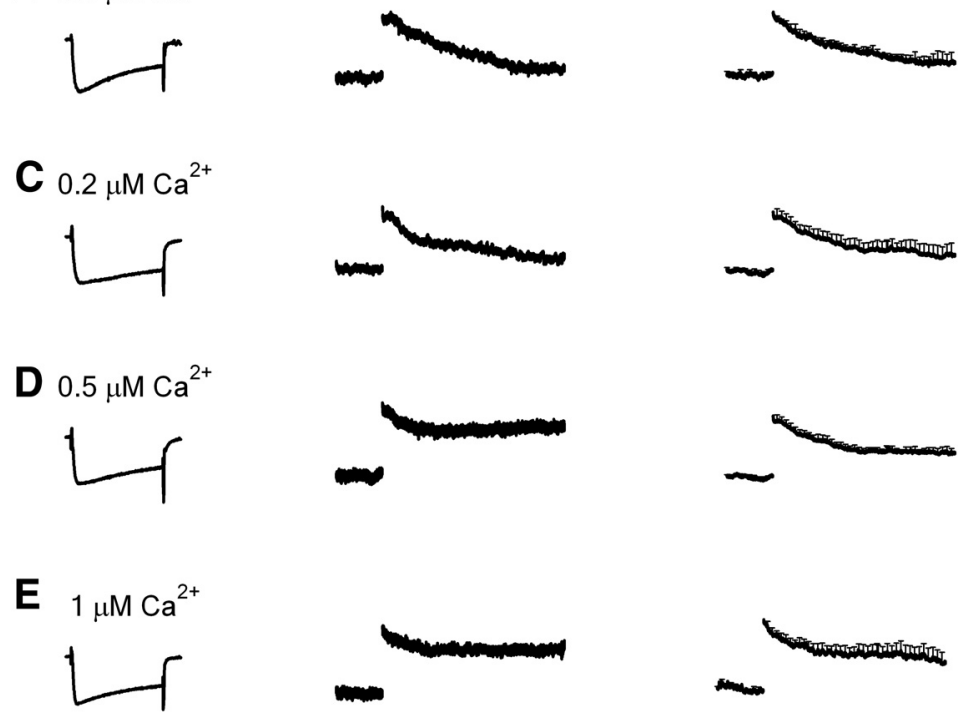

Figure 1. Slow endocytosis at calyces being dialyzed with various concentrations of free calcium. $\boldsymbol{A}$, Left, Sampled $I_{\mathrm{Ca}}$ and the capacitance change $\left(C_{\mathrm{m}}\right)$ induced by depol ${ }_{20 \mathrm{~ms}}$ in control (pipette solution: $0 \mathrm{~mm}$ calcium, $0.05 \mathrm{~mm}$ BAPTA in the pipette). Right, Mean $C_{\mathrm{m}}$ change (mean $+\mathrm{SEM}, n=12$ calyces) induced by a 20 ms depolarization in control (0.05 mm BAPTA). $\boldsymbol{B}-\boldsymbol{E}$, Similar to $\boldsymbol{A}$, except that the pipette contained free calcium at $0.1 \mu \mathrm{M}(\boldsymbol{B}, n=7), 0.2 \mu \mathrm{M}(\boldsymbol{C}, n=9), 0.5 \mu \mathrm{M}(\boldsymbol{D}, n=11)$, and $1 \mu \mathrm{M}(\boldsymbol{E}, n=12)$.

Wu and Betz, 1996; Wu and Borst, 1999; Zucker and Regehr, 2002; Habets and Borst, 2005; Wadel et al., 2007; Xue et al., 2012). We found that prolonged, small, global calcium increase inhibits slow endocytosis, contrasting to the transient, large calcium increase that triggers endocytosis. This opposite effect may reconcile most conflicts regarding calcium's effect on endocytosis.

\section{Materials and Methods}

Animal care and use were performed in accordance with NIH guidelines and approved by the NIH Animal Care and Use Committee. Parasagittal brainstem slices (200 $\mu \mathrm{m}$ thick) containing the medial nucleus of the trapezoid body were prepared from 7- to 10-d-old male or female rats using a vibratome (Sun and Wu, 2001; Sun et al., 2004). Whole-cell capacitance measurements were made with the EPC-9 amplifier together with the software lock-in amplifier (PULSE, HEKA) that implements Lindau-Neher's technique (Sun and Wu, 2001; Sun et al., 2004). The frequency of the sinusoidal stimulus was $1000 \mathrm{~Hz}$ and the peak-to-peak voltage of the sine wave was $\leq 60 \mathrm{mV}$. We pharmacologically isolated presynaptic $\mathrm{Ca}^{2+}$ currents with a bath solution $\left(\sim 22-24^{\circ} \mathrm{C}\right)$ containing the following (in mM): $105 \mathrm{NaCl}, 20 \mathrm{TEA}-\mathrm{Cl}, 2.5 \mathrm{KCl}, 1 \mathrm{MgCl}_{2}, 2 \mathrm{CaCl}_{2}$, $25 \mathrm{NaHCO}_{3}, 1.25 \mathrm{NaH}_{2} \mathrm{PO}_{4}, 25$ glucose, 0.4 ascorbic acid, 3 myo-inositol, 2 sodium pyruvate, 0.001 tetrodotoxin, 0.13 ,4-diaminopyridine, $\mathrm{pH} 7.4$ when bubbled with $95 \% \mathrm{O}_{2}$ and $5 \% \mathrm{CO}_{2}$. The control presynaptic pipette solution contained the following (in $\mathrm{mM}$ ): 125 Cs-gluconate, $20 \mathrm{CsCl}, 4$ MgATP, $10 \mathrm{Na}_{2}$-phosphocreatine, $0.3 \mathrm{GTP}, 10$ HEPES, 0.05 BAPTA, pH 7.2 , adjusted with $\mathrm{CsOH}$. To control the free calcium concentration in the pipette, we replaced BAPTA with different concentrations of EGTA and $\mathrm{CaCl}_{2}$, as described in Results.

As in many previous studies (Wu et al., 2009; Sun et al., 2010; Xue et al., 2012), we measured the initial rate of the capacitance decay after the capacitance jump ( Rate $\left._{\text {decay }}\right)$ as the slope within $4 \mathrm{~s}$ after a $20 \mathrm{~ms}$ depolarization (from -80 to $+10 \mathrm{mV}$, depol $20 \mathrm{~ms}$ ) that induced slow endocytosis, and within $1-1.5 \mathrm{~s}$ after 10 pulses of $20 \mathrm{~ms}$ depolarization at $10 \mathrm{~Hz}$ $\left(\operatorname{depol}_{20 \mathrm{~ms} \times 10}\right)$.

\section{Results}

Calyces were whole-cell voltage-clamped with pipettes containing different concentrations of free calcium. We varied the concentration of the calcium buffer (EGTA or BAPTA) and $\mathrm{Ca}^{2+}\left(\mathrm{CaCl}_{2}\right)$ in the pipette solution in five different combinations to control free calcium concentrations at five different values: (1) $0 \mu \mathrm{M}$ free calcium achieved with $0.05 \mathrm{~mm}$ BAPTA and $0 \mathrm{Ca}^{2+}$, which mimicked the endogenous calcium buffer concentration (Borst et al., 1995; Helmchen et al., 1997) and served as the control; (2) $0.1 \mu \mathrm{M}$ free $\mathrm{Ca}^{2+}\left(2 \mathrm{~mm}\right.$ EGTA and $0.8 \mathrm{mM} \mathrm{Ca}^{2+}$ in the pipette); (3) $0.2 \mu \mathrm{M}$ free $\mathrm{Ca}^{2+}$ (2 mM EGTA and $1.15 \mathrm{mM} \mathrm{Ca}^{2+}$ in the pipette); (4) $0.5 \mu \mathrm{M}$ free $\mathrm{Ca}^{2+}$ (2 mM EGTA and $1.55 \mathrm{mM} \mathrm{Ca}^{2+}$ in the pipette); and (5) 1 $\mu \mathrm{M}$ free $\mathrm{Ca}^{2+}$ (2 mM EGTA and $1.75 \mathrm{~mm}$ $\left.\mathrm{Ca}^{2+}\right)$. The free calcium concentration was calculated based on the Max-Chelator program (Stanford University, Stanford, CA) in which the calcium dissociation constant of EGTA is $0.15 \mu \mathrm{M}$ (Augustine and Neher, 1992; Elhamdani et al., 2006). We had previously confirmed this calculation with fluorescence intracellular calcium measurements (Wu et al., 2009).

To determine how these five different calcium concentrations affect endocytosis, we induced endocytosis with two stimulation protocols, a $20 \mathrm{~ms}$ depolarization $\left(\right.$ depol $\left._{20 \mathrm{~ms}}\right)$ from $-80 \mathrm{mV}$ (holding potential) to $+10 \mathrm{mV}$ (applies if not mentioned), and 10 pulses of $20 \mathrm{~ms}$ depolarization at $10 \mathrm{~Hz}$ $\left(\right.$ depol $\left._{20 \mathrm{~ms} \times 10}\right)$. These two stimuli induce two most widely observed forms of endocytosis, slow and rapid endocytosis, in the control condition with $0.05 \mathrm{~mm}$ BAPTA in the pipette (W. Wu et al., 2005; X.S. Wu et al., 2009). They are equivalent to 10-50 and 200 action potentials at $100-300 \mathrm{~Hz}$, respectively, yet easier for manipulation and measurements of calcium currents $\left(I_{\mathrm{Ca}}\right)$ and endocytosis (W. Wu et al., 2005; X.S. Wu et al., 2009).

\section{Prolonged calcium concentration increase inhibits slow endocytosis}

With $0.05 \mathrm{~mm}$ BAPTA in the pipette, depol $_{20 \mathrm{~ms}}$ induced an $I_{\mathrm{Ca}}$ of $2.3 \pm 0.1 \mathrm{nA}$, a capacitance jump $\left(\Delta C_{\mathrm{m}}\right)$ of $458 \pm 24 \mathrm{fF}$, followed by a slow monoexponential decay with a $\tau$ of $17.2 \pm 3.1 \mathrm{~s}$ and an initial decay rate $\left(\right.$ Rate $_{\text {decay }}$, see Materials and Methods for measurement) of $29 \pm 3 \mathrm{fF} / \mathrm{s}(n=12$, Figs. $1 A, 2 A)$. Although both $\tau$ and Rate decay $_{\text {reflect endocytosis, we used Rate }}$ decay for statistics (W. Wu et al., 2005; X.S. Wu et al., 2009; Sun et al., 2010), because $\tau$ was often too slow to estimate at higher intracellular calcium concentrations as shown later.

With $0.1 \mu \mathrm{M}$ free calcium in the pipette, depol $_{20 \mathrm{~ms}}$ induced an $I_{\mathrm{Ca}}$ and Rate decay similar to those of control (0.05 mM BAPTA, $p=$ $0.17)$, but a $\Delta C_{\mathrm{m}} \sim 81 \%$ of control $(n=7, p<0.01$; Figs. $1 B, 2 A)$. With $0.2 \mu \mathrm{M}$ free calcium in the pipette, $\operatorname{depol}_{20 \mathrm{~ms}}$ induced an $I_{\mathrm{Ca}}$

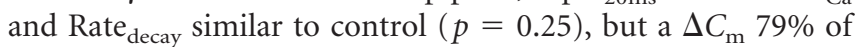
control ( $n=9, p<0.01$; Figs. $1 C, 2 A)$. Similar to control (Fig. $1 A)$, the capacitance decay at $0.1-0.2 \mu \mathrm{M}$ free calcium almost returned to the baseline within $40 \mathrm{~s}$ after stimulation (Fig. $1 B, C$ ). With $0.5 \mu \mathrm{M}$ free calcium in the pipette, depol $_{20 \mathrm{~ms}}$ induced an $I_{\mathrm{Ca}}$ 

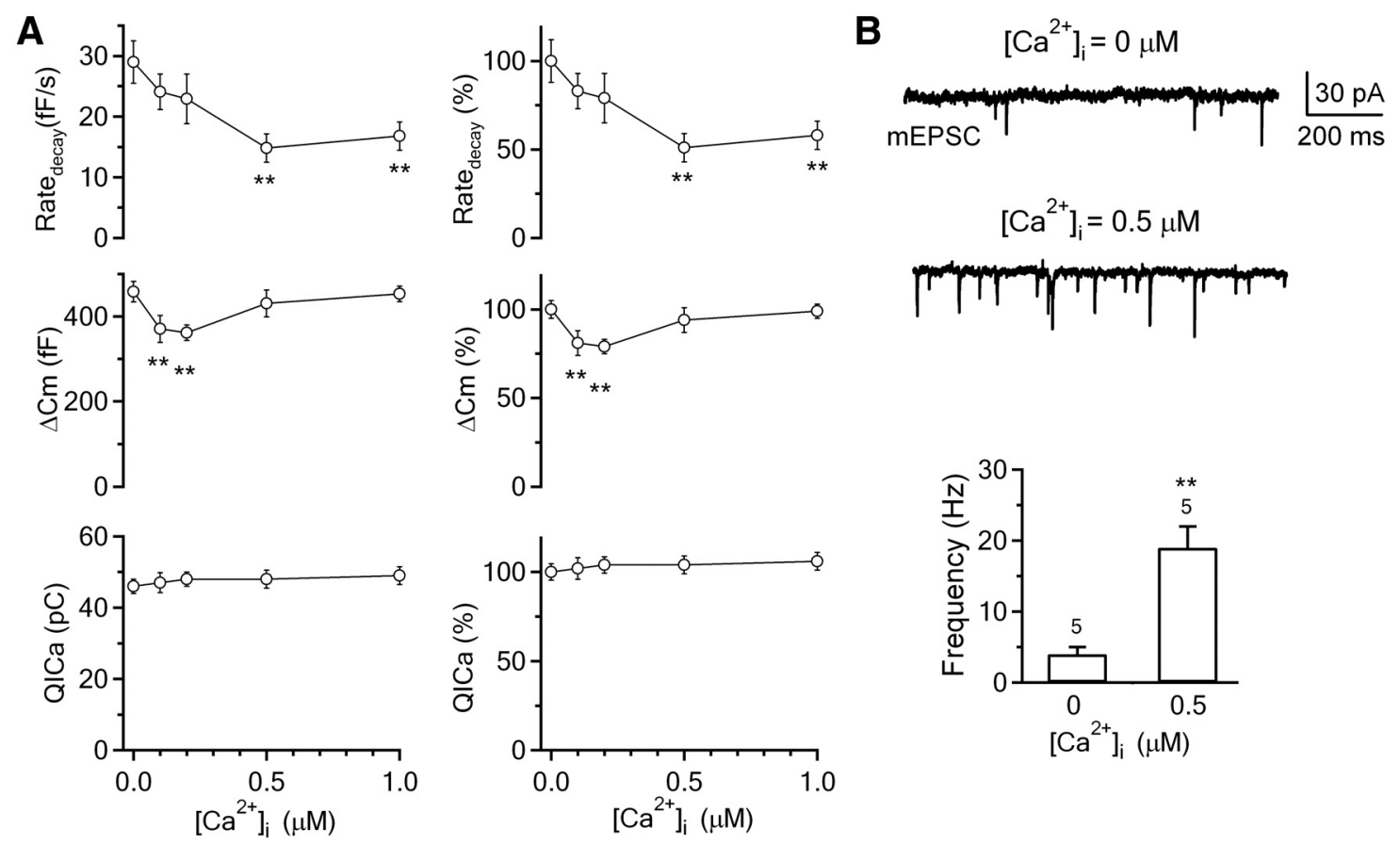

Figure 2. Calcium dialysis into calyces inhibits slow endocytosis in a concentration-dependent manner. $A$, Left, The Rate ${ }_{\text {decay' }} \Delta C_{m^{\prime}}$ and $Q l_{\mathrm{Ca}}$ induced by a 20 ms depolarization with a whole-cell pipette containing free calcium at $0 \mu \mathrm{m}(0.05 \mathrm{~mm}$ BAPTA, $n=12$, control), $0.1 \mu \mathrm{m}(n=7), 0.2 \mu \mathrm{m}(n=9), 0.5 \mu \mathrm{m}(n=11)$, and $1 \mu \mathrm{m}(n=12)$. Right, Same as in left, but with all data normalized to the mean of the control group ( $0 \mu \mathrm{m}$ free calcium). Data are expressed as mean \pm SEM. ${ }^{* *} p<0.01$. B, Sampled postsynaptic recordings of the $\mathrm{mEPSCS}$ and bar graphs showing the $\mathrm{mEPSC}$ frequency differences in calyces dialyzed with $0\left(n=5\right.$ calyces) and $0.5 \mu \mathrm{M}\left(n=5\right.$ calyces) free calcium. ${ }^{* *} p<0.01$.

and $\Delta C_{\mathrm{m}}$ similar to the control $(p>0.06-0.27)$, but a Rate decay $\sim 51 \%$ of control $(n=11, p<0.01)$, and the capacitance decay did not return to the baseline at $40 \mathrm{~s}$ after stimulation (Figs. $1 D$, $2 A$ ). Endocytosis inhibition at $1 \mu \mathrm{M}$ free calcium was similar to that observed at $0.5 \mu \mathrm{M}$ free calcium (Figs. $1 E, 2 A$ ). These results show inhibition of slow endocytosis by the global calcium level in a concentration-dependent manner (Figs. 1, 2A).

The $\sim 20 \%$ decrease in the $\Delta C_{\mathrm{m}}$ at $0.1-0.2 \mu \mathrm{M}$ free calcium (Fig. 2A) was likely due to the increase of the free EGTA concentration. The pipette in control contained only $0.05 \mathrm{~mm}$ BAPTA, whereas at 0.1 or $0.2 \mu \mathrm{M}$ free calcium, the free EGTA concentration was $\sim 1.2 \mathrm{mM}\left(2 \mathrm{~mm}\right.$ EGTA and $0.8 \mathrm{mM} \mathrm{Ca}^{2+}$ in the pipette) or $0.85 \mathrm{~mm}$ (2 $\mathrm{mm}$ EGTA and $1.15 \mathrm{mM} \mathrm{Ca}^{2+}$ in the pipette), respectively. At 0.5 or $1 \mu \mathrm{M}$ free calcium, the free EGTA concentration was reduced to $\sim 0.45 \mathrm{mM}(2 \mathrm{mM}$ EGTA and $1.55 \mathrm{~mm}$ $\mathrm{Ca}^{2+}$ in the pipette) or $0.25 \mathrm{~mm}$ (2 mM EGTA and $1.75 \mathrm{~mm} \mathrm{Ca}^{2+}$ in the pipette), respectively, which may explain why the $\Delta C_{\mathrm{m}}$ was not decreased significantly at $0.5-1 \mu \mathrm{M}$ free calcium compared with control (Fig. 2).

At $0.5 \mu \mathrm{M}$ free calcium, the mEPSC frequency was increased to $\sim 10-20 \mathrm{~Hz}$ (X.S. Wu et al., 2007). To confirm this result, we recorded mEPSCs at the postsynaptic neuron at the whole-cell voltage-clamp configuration while dialyzing 0 or $0.5 \mu \mathrm{M}$ calcium into the corresponding calyx. The mEPSC frequency was $4 \pm 1$ $\mathrm{Hz}(n=5$ synapses $)$ and $19 \pm 3 \mathrm{~Hz}(n=5)$ at 0 and $0.5 \mu \mathrm{M}$ free calcium, respectively (Fig. $2 B$ ), which was in the same range as previously reported (X.S. Wu et al., 2007). This mEPSC frequency increase caused a baseline capacitance increase $(\sim 1 \mathrm{fF} / \mathrm{s})$ (X.S. Wu et al., 2007) too small to affect our measurement of the Rate $_{\text {decay, }}$, which was $\sim 29 \mathrm{fF} / \mathrm{s}$ in control. The capacitance change reflects the net outcome of exocytosis and endocytosis. Would the slower capacitance decay in higher free calcium concentrations (Figs. 1,2) reflect an increase of asynchronous release after depol $_{20 \mathrm{~ms}}$ rather than a slowdown of endocytosis? This possibility is highly unlikely for two reasons. First, the free EGTA concentration $(\sim 0.45-0.25 \mathrm{~mm})$ was actually higher than the control BAPTA concentration $(0.05 \mathrm{~mm})$, which should more effectively prevent residual calcium from generating enormous amounts of asynchronous release to offset the capacitance decay. Second, if asynchronous release induced by depol $_{20 \mathrm{~ms}}$ was responsible for the slower capacitance decay, more asynchronous release induced by a stronger stimulus, depol $_{20 \mathrm{~ms} \times 10}$, should cause slower capacitance decay. This prediction was incorrect. As described below, the capacitance increase after $\operatorname{depol}_{20 \mathrm{~ms} \times 10}$ returned to the baseline with a similar time course in various free calcium concentrations ranging from 0 to $1 \mu \mathrm{M}$ (see Figs. 3, 4 for detail).

\section{Prolonged calcium concentration increase does not inhibit endocytosis induced by strong stimulation}

Next, we studied how calcium dialysis affects endocytosis induced by a more intense stimulation, the $\operatorname{depol}_{20 \mathrm{~ms} \times 10}$. In control, depol ${ }_{20 \mathrm{~ms} \times 10}$ induced a $\Delta C_{\mathrm{m}}$ of $1598 \pm 117 \mathrm{fF}$, followed by a biexponential decay with $\tau$ of $2.4 \pm 0.4 \mathrm{~s}$ (weight, $29 \pm 3 \%$ ) and $18 \pm 3.5 \mathrm{~s}(n=12$, Fig. $3 A)$. Rate decay after $\operatorname{depol}_{20 \mathrm{~ms} \times 10}$ was $223 \pm 28 \mathrm{fF} / \mathrm{s}(n=12$, Figs. $3 A, 4)$, which reflected mostly $(>80 \%)$ the rapid component of endocytosis (W. Wu et al., 2005; X.S. Wu et al., 2009; Sun et al., 2010). When the pipette free calcium concentration was $0.1 \mu \mathrm{M}$ (Fig. 3B), $0.2 \mu \mathrm{M}$ (Fig. 3C), 0.5 $\mu \mathrm{M}$ (Fig. 3D), and $1 \mu \mathrm{M}$ (Fig. $3 E$ ), $\Delta C_{\mathrm{m}}$ and Rate ${ }_{\text {decay }}$ did not change significantly in most conditions ( $p>0.05$; Figs. 3,4$)$, except that $\Delta C_{\mathrm{m}}$ was slightly reduced at $0.2 \mu \mathrm{M}$ free calcium $(p<$ 0.05 ; Fig. 4 ), likely due to the relatively high free EGTA concentration. The slow component of endocytosis induced by depol $_{20 \mathrm{~ms} \times 10}$ was not affected either (Fig. 3). These results suggest that prolonged calcium increase up to $1 \mu \mathrm{M}$ does not affect either rapid or slow endocytosis induced by stronger intensity of stimulation. Inhibition of endocytosis by prolonged, small, 


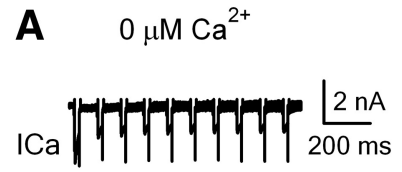

B

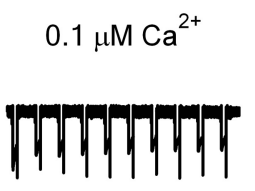

C

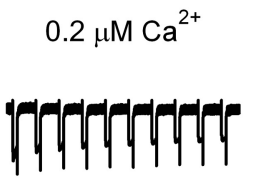

D

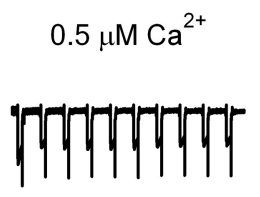

E

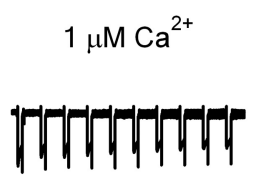

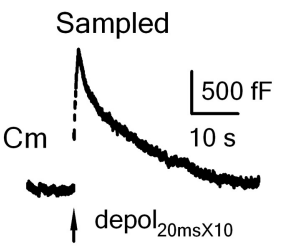
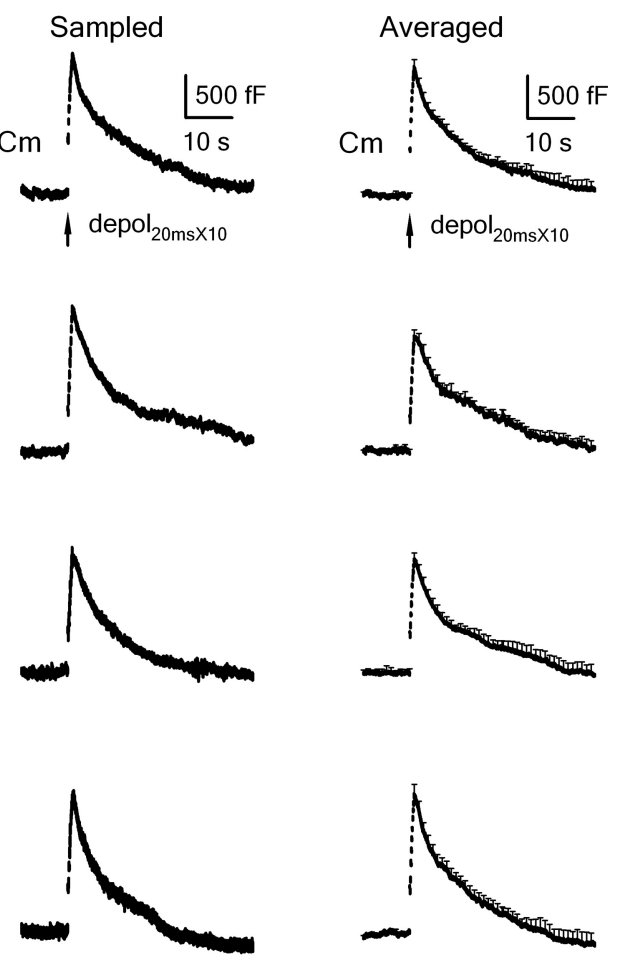

Figure 3. Rapid endocytosis in calyces being dialyzed with various concentrations of calcium. $\boldsymbol{A}$, Left, Sampled $I_{\text {ca }}$ and the capacitance change $\left(C_{\mathrm{m}}\right)$ induced by depol $\mathrm{I}_{20 \mathrm{~ms} \times 10}$ in control (pipette solution: $0 \mathrm{~mm}$ calcium, $0.05 \mathrm{~mm}$ BAPTA in the pipette). Right, Mean $C_{\mathrm{m}}$ change (mean + SEM, $n=12$ calyces) induced by depol $20 \mathrm{~ms} \times 10$ in control ( $0.05 \mathrm{~mm}$ BAPTA). $\boldsymbol{B}-\boldsymbol{E}$, Similar to $\boldsymbol{A}$, except that the pipette contained free calcium at $0.1 \mu \mathrm{M}(\boldsymbol{B}, n=7), 0.2 \mu \mathrm{M}(\boldsymbol{C}, n=9), 0.5 \mu \mathrm{M}(\boldsymbol{D}, n=11)$, and $1 \mu \mathrm{M}(\boldsymbol{E}, n=12)$. if a depol $20 \mathrm{~ms}$ was applied at $3 \mathrm{~s}$ after the APe train. Similar subtraction was applied to measure the Rate ${ }_{\text {decay }}$ within $1-1.5 \mathrm{~s}$ after $\operatorname{depol}_{20 \mathrm{~ms} \times 10}$ (Fig. 5C). With these calculation methods, we found that following the APe train, the Rate decay $_{\text {induced by }}$ $\operatorname{depol}_{20 \mathrm{~ms}}(12 \pm 2 \mathrm{fF} / \mathrm{s}, n=8)$ was much smaller than that in control without the preceding APe train $(29 \pm 3 \mathrm{fF} / \mathrm{s}, n=12$, $p<0.01)$, whereas the Rate decay $_{\text {after }}$ $\operatorname{depol}_{20 \mathrm{~ms} \times 10}(237 \pm 18 \mathrm{fF} / \mathrm{s}, n=8)$ was similar to the control $(223 \pm 28 \mathrm{fF} / \mathrm{s}, n=$ $12, p=0.42$; see bar graphs in Fig. $5 D$ ). Thus, APe train mimicked calcium dialysis in inhibiting slow, but not fast endocytosis, which suggests that physiological stimulus may inhibit slow endocytosis by increasing the global calcium level.

\section{Relation between endocytosis time constant and the step depolarization duration}

We showed that prolonged APe trains inhibit slow endocytosis (Fig. 5), likely by increasing the global calcium concentration, which is different from acceleration of endocytosis by large, local calcium increase at calyces (Hosoi et al., 2009; Wu et al., 2009; Yamashita et al., 2010). Thus, it seems obvious that the net outcome between inhibition and acceleration of endocytosis may determine the endocytosis rate. In support of this possibility, we found, as described below, that as the depolarization duration increased from 2 to $200 \mathrm{~ms}$, slow endocytosis was slowed down, whereas rapid endocytosis was activated as the depolarization duration was

global calcium increase as observed in Figures 1 and 2 is therefore limited to intermediate stimulation intensities.

\section{A train of action potential-like stimuli inhibits slow, but not fast endocytosis}

We showed that persistent calcium concentration increase inhibits slow, but not fast endocytosis. To mimic prolonged calcium concentration increase in physiological conditions, we applied 100 action potential-equivalent (APe) stimuli at $20 \mathrm{~Hz}$ using a control pipette containing $0 \mu \mathrm{M}$ calcium $(0.05 \mathrm{~mm}$ BAPTA; Fig. $5 A)$. APe was mimicked as a $1 \mathrm{~ms}$ depolarization from -80 to +7 $\mathrm{mV}$, which induced a presynaptic $I_{\mathrm{Ca}}$ and a postsynaptic EPSC similar to an action potential (Sun et al., 2002; Xu and Wu, 2005). At $3 \mathrm{~s}$ after applying this APe train, we applied $\operatorname{depol}_{20 \mathrm{~ms}}$ (Fig. $5 B$ ) or $\operatorname{depol}_{20 \mathrm{~ms} \times 10}$ (Fig. 5C) to determine whether Rate ${ }_{\text {decay }}$ is reduced compared with the control without the preceding train. The control traces are shown in Figures $1 A$ and $3 A$, and their mean Rat$\mathrm{e}_{\text {decay }}$ values are shown in Figures $2 A$ and 4 . The Rate decay $_{\text {after }}$ depol $_{20 \mathrm{~ms}}$ (with preceding APe train) was calculated as the rate of decay within $4 \mathrm{~s}$ after depol $20 \mathrm{~ms}$ (Fig. $5 \mathrm{~B}$, red line) subtracted by the rate of decay within 3-7 s after $100 \mathrm{APe}$ at $20 \mathrm{~Hz}$ was applied alone at the same cell (Fig. $5 A, B$, green line). This subtraction was necessarily because the $100 \mathrm{APe}$ alone induced a non-negligible capacitance decay of $20 \pm 4 \mathrm{fF} / \mathrm{s}(n=8)$ at 3-7 s after the stimulation, the same time window in which we measured the Rate decay prolonged to $200 \mathrm{~ms}$.

We applied 2, 5, 10, 20, 50, or $200 \mathrm{~ms}$ depolarization from -80 to $+10 \mathrm{mV}$ to the calyx via control pipettes containing $0 \mu \mathrm{M}$ free calcium. As the depolarization duration increased, the $Q I_{\mathrm{Ca}}$ increased, the $\Delta C_{\mathrm{m}}$ increased, and the $\tau$ of the capacitance decay increased (Fig. $6 A-F$, summarized in Fig. $6 G, H$ ). Notice here that

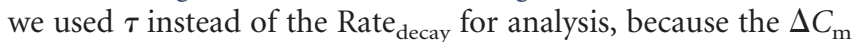
differed by severalfold (Fig. $6 A-F$ ), which made the comparison of the Rate decay $_{\text {not meaningful. }}$

The near-linear relation between the endocytic $\tau$ and the $\Delta C_{\mathrm{m}}$ (Fig. 6G) was consistent with previous findings that increasing the depolarization duration from 1 to $20 \mathrm{~ms}$ increases the $\Delta C_{\mathrm{m}}$ and the endocytosis $\tau$ at calyces (Sun et al., 2002; Wu et al., 2005; Yamashita et al., 2005; Renden and von Gersdorff, 2007). This observation was previously interpreted as reflecting saturation of the endocytic machinery (Sankaranarayanan and Ryan, 2000), but could now be reinterpreted as reflecting inhibition of endocytosis by global calcium increase, because the endocytic $\tau$ increased as $Q I_{\mathrm{Ca}}$ increased (Fig. $6 \mathrm{H}$ ). Although our results do not allow us to fully exclude saturation as an interpretation, we prefer our interpretation of calcium-dependent inhibition, because there has been no direct evidence showing that the endocytic capacity can be saturated, whereas we showed directly that prolonged calcium increase inhibited slow endocytosis (Fig. 1). 

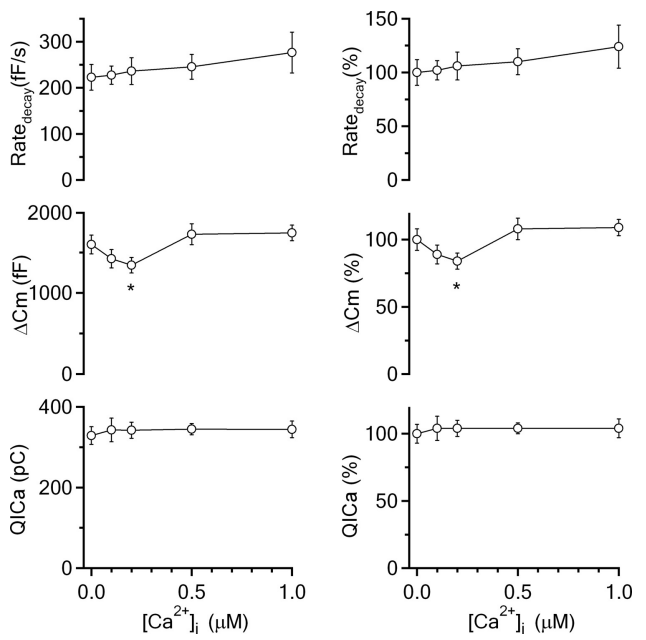

Figure 4. Calcium dialysis into calyces does not inhibit rapid endocytosis. Left, The Rate decay' $\Delta C_{m}$, and $Q l_{C a}$ induced by depol $\mathrm{I}_{20 \mathrm{~ms} \times 10}$ with a pipette containing free calcium at $0 \mu \mathrm{M}(0.05$ $\mathrm{mm}$ BAPTA, $n=12), 0.1 \mu \mathrm{m}(n=7), 0.2 \mu \mathrm{m}(n=9), 0.5 \mu \mathrm{m}(n=11)$, and $1 \mu \mathrm{m}(n=12)$. Right, Same as in left, but with all data normalized to the mean of the control group ( $0 \mu \mathrm{m}$ free calcium). Data are expressed as mean \pm SEM. ${ }^{*} p<0.05$.

Whereas the capacitance decay was monoexponential after 2-50 ms depolarization (Fig. 6A-E), it was biexponential with $\tau$ of $1.1 \pm 0.2 \mathrm{~s}$ (weight, $20 \pm 4 \%)$ and $23 \pm 2 \mathrm{~s}(n=8)$ after $200 \mathrm{~ms}$ depolarization (Fig. $6 F$ ). The $\tau$ of the rapid component $(1.1 \pm$ $0.2 \mathrm{~s}$ ) was not included in the summary plot in Figure $6, G$ and $H$. The appearance of this rapid component is consistent with the previous finding that a larger increase of the calcium influx triggers rapid endocytosis (W. Wu et al., 2005; X.S. Wu et al., 2009). For example, as the pulse duration increases from 2 to $50 \mathrm{~ms}$ during 10 pulses of depolarization at $10 \mathrm{~Hz}$, calcium influx is increased, rapid endocytosis is activated, and its $\tau$ decreases ( $\mathrm{Wu}$ et al., 2009). Rapid endocytosis is more often observed when the intracellular calcium concentration increase induced by photolysis of a caged calcium compound is tens of micromolar or higher in hair cells (Beutner et al., 2001). Thus, 200 ms depolarization may increase the local calcium concentration above the threshold to activate rapid endocytosis. Local, transient saturation of the calcium buffer by $200 \mathrm{~ms}$ depolarization, but not by shorter duration of depolarization, might further contribute to the local calcium concentration increase (Felmy et al., 2003), and thus activation of rapid endocytosis.

In summary, as the depolarization duration and, thus, $Q I_{\mathrm{Ca}}$ increased, the $\tau$ of the slow endocytosis increased, and a rapid component of endocytosis occurred (Fig. 6). These results can be explained by the global calcium increase that inhibits slow endocytosis, and the local calcium increase that activates rapid endocytosis.

\section{Discussion}

At calyx nerve terminals, we found that prolonged calcium increase from 0 to $1 \mu \mathrm{M}$ inhibited slow endocytosis in a concentrationdependent manner (Figs. 1, 2). APe trains also inhibited slow endocytosis (Fig. 5), suggesting that global calcium increase induced by physiological stimulation may inhibit slow endocytosis. These results are in contrast to the recent finding that the transient calcium concentration increase to more than $\sim 10 \mu \mathrm{M}$ at the calcium micro/nano domain triggers slow endocytosis (Hosoi et al., 2009; Wu et al., 2009; Yamashita et al., 2010). Together, our results show that transient, large calcium influx at the micro/ nano domain, as induced by action potentials, triggers slow en-
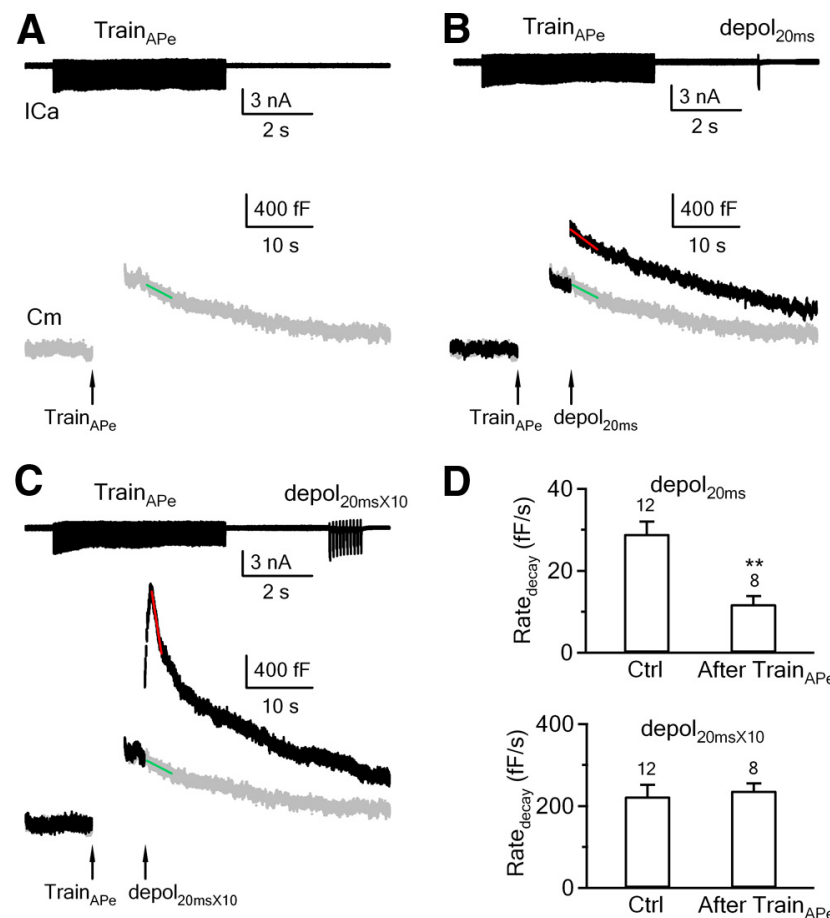

D
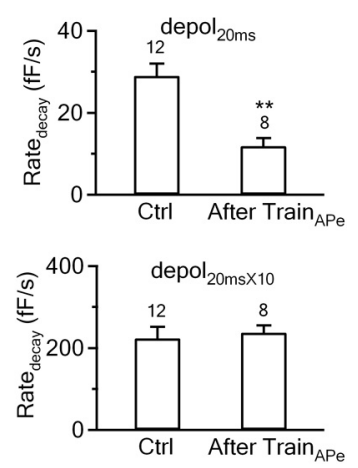

Figure 5. An APe train causes inhibition of slow, but not rapid endocytosis. $A$, Sampled $I_{C a}$ and $C_{m}$ trace (gray trace) in response to $100 \mathrm{APe}$ at $20 \mathrm{~Hz}$ (Train APe $_{\text {e }}$. The pipette contained $0 \mu \mathrm{m}$ calcium (0.05 mm BAPTA, applies to $\boldsymbol{A}-\boldsymbol{C}$ ). The green line is the linear fit of the capacitance decay within 3-7 s after $\operatorname{Train}_{\mathrm{APe}}$. $\boldsymbol{B}$, Sampled $I_{\mathrm{Ca}}$ and $C_{\mathrm{m}}$ traces in response to a depol ${ }_{20 \mathrm{~ms}}$ applied $3 \mathrm{~s}$

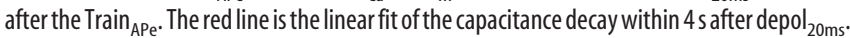
The gray trace (and the green line) is the $C_{m}$ trace caused by Train ${ }_{\text {APe }}$ alone (same as in $A$ ). The difference between the slope of the red and the green line is the Rate ${ }_{\text {decay }}$ induced by a depo $_{20 \mathrm{~ms}}$ applied 3 safter a Train ${ }_{\mathrm{APe}}$. C, Sampled $I_{\mathrm{Ca}}$ and $C_{\mathrm{m}}$ traces in response to a depol $\mathrm{I}_{20 \mathrm{~ms} \times 10}$

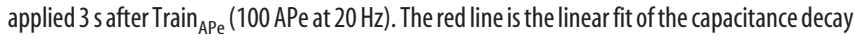
within $1.5 \mathrm{~s}$ after depol $\mathrm{I}_{20 \mathrm{~ms} \times 10}$. The gray trace (and the green line) is the $C_{\mathrm{m}}$ trace caused by Train $_{A P e}$ alone (same as in $\boldsymbol{A}$ ). The difference between the slope of the red and the green line is the Rate decay $_{\text {induced by a depo }}$ 20ms $\times 10_{10}$ applied $3 \mathrm{~s}$ after the $\operatorname{Train}_{\mathrm{APe}} \cdot \boldsymbol{A}$-C were from the same calyx. D, Rate decay $_{\text {induced by depol }} 20 \mathrm{~ms}$ (top) and depol $\mathrm{I}_{20 \mathrm{~ms} \times 10}$ (bottom) in control (Ctrl, no preceding APe train) and at $3 \mathrm{~s}$ after $100 \mathrm{APe}$ train at $20 \mathrm{~Hz}$ (Train $\left.{ }_{\mathrm{APe}}\right)$. The calyx numbers are labeled in the bar graph. The control data are taken from Figures $1 A$ and $3 A$. ${ }^{* *} p<0.01$.

docytosis, whereas prolonged, small, and global calcium increase, as can be induced by action potential trains, inhibits slow endocytosis. Such a yin and yang effect of calcium on endocytosis is likely to have wide application beyond the large calyx nerve terminal, and may reconcile most conflicts in the literature regarding whether calcium facilitates or inhibits endocytosis.

\section{Reconciling apparent conflicts at goldfish ribbon-type synapses}

At the goldfish retinal bipolar nerve terminal, a pioneering study two decades ago found that calcium dialysis $>1 \mu \mathrm{M}$ abolishes rapid endocytosis, leading to the conclusion that calcium inhibits rapid endocytosis (von Gersdorff and Matthews, 1994). A subsequent study 7 years later showed that buffering calcium influx with EGTA blocks fast, but not slow endocytosis induced by brief depolarization, leading to the opposite conclusion that calcium selects rapid endocytosis (Neves et al., 2001). This apparent conflict can now be reconciled with our finding that prolonged, small, global calcium increase inhibits endocytosis, whereas large, transient calcium increase triggers endocytosis.

\section{Comparing the present work with a study in goldfish retina}

Although our observation that calcium dialysis inhibits slow endocytosis seems analogous to an early study in goldfish retina 

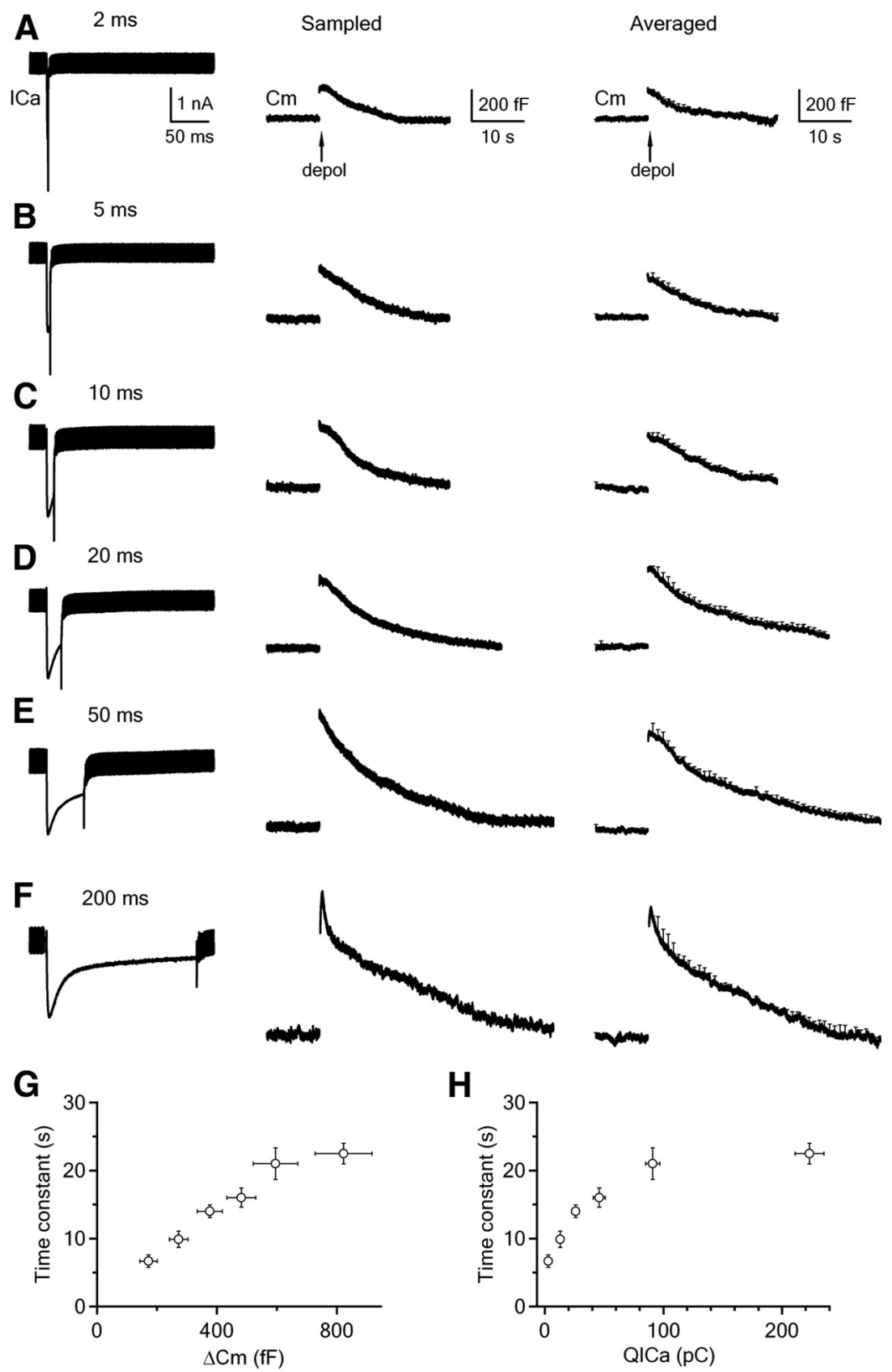

Figure 6. Endocytosis induced by $2-200 \mathrm{~ms}$ depolarization. $\boldsymbol{A}-\boldsymbol{F}$, Sampled $I_{\mathrm{Ca}}$ (left), sampled $C_{\mathrm{m}}$ trace (middle), and averaged $\boldsymbol{C}_{\mathrm{m}}$ trace (right) induced by $2(\boldsymbol{A}, n=9), 5(\boldsymbol{B}, n=10), 10(\boldsymbol{C}, n=9), 20(\boldsymbol{D}, n=9), 50(\boldsymbol{E}, n=8)$, and $200 \mathrm{~ms}(\boldsymbol{F}, n=8)$ depolarization from -80 to $+10 \mathrm{mV}$. The scale bars in $\boldsymbol{A}$ apply to $\boldsymbol{A}-\boldsymbol{F}$. $\boldsymbol{G}, \boldsymbol{H}$, The capacitance decay (endocytosis) $\tau$ is plotted versus the $\Delta C_{\mathrm{m}}(\boldsymbol{G})$ and $Q \mathrm{C}_{\mathrm{Ca}_{\mathrm{a}}}(\boldsymbol{H})$ induced by $2,5,10,20,50$, and $200 \mathrm{~ms}$ depolarization (data taken from those shown in $\boldsymbol{A}-\boldsymbol{F}$ ). For $200 \mathrm{~ms}$ depolarization, the $\tau$ of the slow, but not the fast component is included. Data are expressed as mean \pm SEM. The number of calyces for each depolarization pulse is described in $\boldsymbol{A}-\boldsymbol{F}$.

(von Gersdorff and Matthews, 1994), the present work is an advance over this early study in three aspects. First, conclusions are different. We suggest that only the prolonged, small, global calcium increase, but not all patterns of calcium increase as proposed in the early study, inhibits endocytosis. Second, we showed that slow endocytosis, the most commonly observed endocytic form, is inhibited by calcium dialysis at mammalian central synapses containing conventional active zones, whereas the early study shows that rapid endocytosis is inhibited by calcium dialysis at goldfish ribbon-type synapses. Third, we found that upon stronger stimulation $\left(\operatorname{depol}_{20 \mathrm{~ms} \times 10}\right)$, both rapid and slow forms of endocytosis were not inhibited by calcium dialysis (Figs. 3, 4).
This result suggests that large, transient calcium influx at the micro/nano domain may overcome the inhibitory effect of prolonged, global calcium increase. Inhibition of endocytosis by calcium dialysis may therefore be limited to mild to intermediate levels of stimulation.

\section{Reconciling apparent conflicts at conventional synapses}

Reducing the extracellular calcium or buffering calcium influx slows down or abolishes endocytosis at hippocampal synapses and calyces (Sankaranarayanan and Ryan, 2001; Wu et al., 2009; Sun et al., 2010), whereas prolonging the stimulation train increases calcium influx, but prolongs endocytosis in many preparations, such as frog neuromuscular junctions (Wu and Betz, 1996), hippocampal synapses (Sankaranarayanan and Ryan, 2000; Balaji et al., 2008; Sun et al., 2010), calyces (Sun et al., 2002; Wu et al., 2005; Yamashita et al., 2005; Renden and von Gersdorff, 2007), and chromaffin cells (Artalejo et al., 1995; Elhamdani et al., 2006). These paradoxical results can be interpreted with the yin and yang effect of calcium: reducing extracellular calcium or buffering calcium with BAPTA may inhibit endocytosis by reducing the transient calcium increase at the micro/nano domain, whereas prolonging the stimulation train may prolong endocytosis by increasing the global calcium concentration. The transient calcium increase to tens of micromolar at the micro/nano domain dissipates mostly in $\sim 10 \mathrm{~ms}$ after an action potential (Bollmann and Sakmann, 2005; Neher and Sakaba, 2008), but may dissipate more slowly after prolonged depolarization. Rapid dissipation may lead to little calcium accumulation at the micro/nano domain during action potential trains at $30 \mathrm{~Hz}$ or less and during 20-50 ms depolarization trains at $<1 \mathrm{~Hz}$. However, these relatively low-frequency stimuli may induce global calcium increase to $\sim 0.2-1 \mu \mathrm{M}$ for $\sim 30 \mathrm{~s}$ to minutes, as demonstrated at many nerve terminals (Kamiya and Zucker, 1994; Wu and Betz, 1996; Wu and Borst, 1999; Zucker and Regehr, 2002; Habets and Borst, 2005; Wadel et al., 2007; Xue et al., 2012), which may explain why endocytosis is prolonged after a longer train of stimulation. In contrast to lower-frequency stimulation, higherfrequency stimulation may induce substantial accumulation of calcium to tens of micromolar at the transient micro/nano domain, which may explain why action potential-equivalent stimuli at $100-300 \mathrm{~Hz}$ or $20-50 \mathrm{~ms}$ depolarization at $10 \mathrm{~Hz}$ speeds up endocytosis at calyces (W. Wu et al., 2005; X.S. Wu et al., 2009). Saturation of the calcium buffer because of massive calcium influx and insufficient time to pump out intracellular calcium may 
further contribute to the transient calcium increase at the micro/ nano domain during higher-frequency stimulation (Felmy et al., 2003), which may further promote facilitation of endocytosis.

A recent study shows that endocytosis is speeded up in the first few action potentials, and then slowed down during prolonged lower-frequency $(10 \mathrm{~Hz})$ action potential trains (Armbruster et al., 2013). The speed-up of endocytosis could be accounted for by facilitation of endocytosis by the large calcium transient at the micro/nano domain, if facilitation of endocytosis continues for a short time after calcium microdomain dissipates. The slowdown of endocytosis could be due to prolonged, global calcium increase that inhibits endocytosis.

In summary, whether endocytosis is upregulated or downregulated may depend on the net outcome between facilitation by transient calcium micro/nano domain and inhibition by prolonged global calcium increase, which in turn depends on the stimulation frequency and duration of depolarization. These mechanisms may explain most apparent conflicts in the last two decades of studies regarding whether calcium upregulates or downregulates endocytosis. They may also provide an explanation for why the increase of the depolarization duration from 2 to $200 \mathrm{~ms}$ prolonged slow endocytosis, but activated a rapid component of endocytosis at calyces (Fig. 6).

\section{What are the mechanisms underlying the opposite effects of calcium on endocytosis?}

The present work raises the question as to what underlies the opposite effects of calcium on endocytosis. The yin and yang effect of the same factor has been reported in many systems. For example, long-term potentiation and depression of synaptic transmission are both induced by calcium, but at different patterns of stimulation (Malenka and Bear, 2004). Currently, we do not know how calcium exerts the opposite effects on endocytosis. Many potential mechanisms can be considered. Here we discuss two scenarios, which certainly would not exhaust all possibilities. First, prolonged calcium increase might interrupt the cycling of calcium-dependent phosphorylation and dephosphorylation of endocytic proteins. It has been suggested that calcium/calmodulin activates calcineurin to dephosphorylate endocytic proteins, including dynamin, which is needed to mediate and to facilitate slow endocytosis (Marks and McMahon, 1998; Cousin and Robinson, 2001; Wu et al., 2009; Sun et al., 2010; Xue et al., 2011; Armbruster et al., 2013). If prolonged calcium increase causes more calcium-dependent phosphorylation than dephosphorylation of endocytic proteins, it may explain why prolonged calcium increase inhibits endocytosis. Second, while large, transient calcium increase may trigger endocytosis, prolonged, small calcium increase may activate calcium-dependent chloride channels to increase intracellular chloride concentration, which has been shown to inhibit endocytosis at the goldfish retinal bipolar synapse (Hull and von Gersdorff, 2004). It would be of great interest to understand how prolonged, small calcium increase and transient, large calcium increase exert opposite effects in regulating endocytosis in the future.

\section{Does yin and yang of calcium apply to all forms of endocytosis at the single-vesicle level?}

At the single-vesicle level, there are three mechanistically different forms of endocytosis, classical clathrin-dependent endocytosis, kiss-and-run, and bulk endocytosis which forms a large endosome-like structure (L.G. Wu et al., 2007; Alabi and Tsien, 2013). Dialysis of blockers of clathrin-dependent endocytosis in- hibits slow endocytosis at calyces, suggesting that slow endocytosis at calyces is clathrin dependent (Hosoi et al., 2009; Wu et al., 2009). Recent studies show that slow endocytosis is triggered by calcium influx at the micro/nano domain at calyces (Hosoi et al., 2009; Wu et al., 2009). Thus, the yin (inhibition by prolonged global calcium) and yang (trigger and facilitation by transient local calcium) of calcium on endocytosis may apply to clathrindependent endocytosis.

We recently found that transient calcium influx triggers all forms of endocytosis recorded at the whole-cell configuration, including slow endocytosis, bulk endocytosis, rapid endocytosis and endocytosis overshoot at calyces (Wu et al., 2009). It remains unclear whether transient local calcium influx triggers and facilitates kiss-and-run, and whether global calcium increase inhibits kiss-and-run and/or bulk endocytosis. Addressing these questions in the future may answer whether the yin and yang effect of calcium applies to kiss-and-run and bulk endocytosis.

\section{References}

Alabi AA, Tsien RW (2013) Perspectives on kiss-and-run: role in exocytosis, endocytosis, and neurotransmission. Annu Rev Physiol 75:393-422. CrossRef Medline

Armbruster M, Messa M, Ferguson SM, De Camilli P, Ryan TA (2013) Dynamin phosphorylation controls optimization of endocytosis for brief action potential bursts. Elife 2:e00845. CrossRef Medline

Artalejo CR, Henley JR, McNiven MA, Palfrey HC (1995) Rapid endocytosis coupled to exocytosis in adrenal chromaffin cells involves $\mathrm{Ca}^{2+}, \mathrm{GTP}$, and dynamin but not clathrin. Proc Natl Acad Sci U S A 92:8328-8332. CrossRef Medline

Augustine GJ, Neher E (1992) Calcium requirements for secretion in bovine chromaffin cells. J Physiol 450:247-271. Medline

Balaji J, Armbruster M, Ryan TA (2008) Calcium control of endocytic capacity at a CNS synapse. J Neurosci 28:6742-6749. CrossRef Medline

Beutner D, Voets T, Neher E, Moser T (2001) Calcium dependence of exocytosis and endocytosis at the cochlear inner hair cell afferent synapse. Neuron 29:681-690. CrossRef Medline

Bollmann JH, Sakmann B (2005) Control of synaptic strength and timing by the release-site $\mathrm{Ca}^{2+}$ signal. Nat Neurosci 8:426-434. CrossRef Medline

Borst JGG, Helmchen F, Sakmann B (1995) Pre- and postsynaptic wholecell recordings in the medial nucleus of the trapezoid body of the rat. J Physiol 489:825-840. Medline

Ceccarelli B, Hurlbut WP (1980) $\mathrm{Ca}^{2+}$-dependent recycling of synaptic vesicles at the frog neuromuscular junction. J Cell Biol 87:297-303. CrossRef Medline

Cousin MA, Robinson PJ (1998) $\mathrm{Ba}^{2+}$ does not support synaptic vesicle retrieval in rat cerebrocortical synaptosomes. Neurosci Lett 253:1-4. CrossRef Medline

Cousin MA, Robinson PJ (2001) The dephosphins: dephosphorylation by calcineurin triggers synaptic vesicle endocytosis. Trends Neurosci 24: 659-665. CrossRef Medline

Elhamdani A, Azizi F, Artalejo CR (2006) Double patch clamp reveals that transient fusion (kiss-and-run) is a major mechanism of secretion in calf adrenal chromaffin cells: high calcium shifts the mechanism from kissand-run to complete fusion. J Neurosci 26:3030-3036. CrossRef Medline

Felmy F, Neher E, Schneggenburger R (2003) Probing the intracellular calcium sensitivity of transmitter release during synaptic facilitation. Neuron 37:801-811. CrossRef Medline

Habets RL, Borst JG (2005) Post-tetanic potentiation in the rat calyx of Held synapse. J Physiol 564:173-187. CrossRef Medline

Helmchen F, Borst JGG, Sakmann B (1997) Calcium dynamics associated with a single action potential in a CNS presynaptic terminal. Biophys J 72:1458-1471. CrossRef Medline

Henkel AW, Betz WJ (1995) Monitoring of black widow spider venom (BWSV) induced exo- and endocytosis in living frog motor nerve terminals with FM1-43. Neuropharmacology 34:1397-1406. CrossRef Medline

Hosoi N, Holt M, Sakaba T (2009) Calcium dependence of exo- and endocytotic coupling at a glutamatergic synapse. Neuron 63:216-229. CrossRef Medline

Hull C, von Gersdorff H (2004) Fast endocytosis is inhibited by GABA- 
mediated chloride influx at a presynaptic terminal. Neuron 44:469-482. CrossRef Medline

Kamiya H, Zucker RS (1994) Residual $\mathrm{Ca}^{2+}$ and short-term synaptic plasticity. Nature 371:603-606. CrossRef Medline

Leitz J, Kavalali ET (2011) Ca(2) influx slows single synaptic vesicle endocytosis. J Neurosci 31:16318-16326. CrossRef Medline

Malenka RC, Bear MF (2004) LTP and LTD: an embarrassment of riches. Neuron 44:5-21. CrossRef Medline

Marks B, McMahon HT (1998) Calcium triggers calcineurin-dependent synaptic vesicle recycling in mammalian nerve terminals. Curr Biol 8:740-749. CrossRef Medline

Moser T, Beutner D (2000) Kinetics of exocytosis and endocytosis at the cochlear inner hair cell afferent synapse of the mouse. Proc Natl Acad Sci U S A 97:883-888. CrossRef Medline

Neher E, Sakaba T (2008) Multiple roles of calcium ions in the regulation of neurotransmitter release. Neuron 59:861-872. CrossRef Medline

Neves G, Gomis A, Lagnado L (2001) Calcium influx selects the fast mode of endocytosis in the synaptic terminal of retinal bipolar cells. Proc Natl Acad Sci U S A 98:15282-15287. CrossRef Medline

Renden R, von Gersdorff H (2007) Synaptic vesicle endocytosis at a CNS nerve terminal: faster kinetics at physiological temperatures and increased endocytotic capacity during maturation. J Neurophysiol 98:3349-3359. CrossRef Medline

Sankaranarayanan S, Ryan TA (2000) Real-time measurements of vesicleSNARE recycling in synapses of the central nervous system. Nat Cell Biol 2:197-204. CrossRef Medline

Sankaranarayanan S, Ryan TA (2001) Calcium accelerates endocytosis of vSNAREs at hippocampal synapses. Nat Neurosci 4:129-136. CrossRef Medline

Sun JY, Wu LG (2001) Fast kinetics of exocytosis revealed by simultaneous measurements of presynaptic capacitance and postsynatpic currents at a central synapse. Neuron 30:171-182. Medline

Sun JY, Wu XS, Wu LG (2002) Single and multiple vesicle fusion induce different rates of endocytosis at a central synapse. Nature 417:555-559. CrossRef Medline

Sun JY, Wu XS, Wu W, Jin SX, Dondzillo A, Wu LG (2004) Capacitance measurements at the calyx of Held in the medial nucleus of the trapezoid body. J Neurosci Methods 134:121-131. CrossRef Medline

Sun T, Wu XS, Xu J, McNeil BD, Pang ZP, Yang W, Bai L, Qadri S, Molkentin JD, Yue DT, Wu LG (2010) The role of calcium/calmodulin-activated calcineurin in rapid and slow endocytosis at central synapses. J Neurosci 30:11838-11847. CrossRef Medline

von Gersdorff H, Matthews G (1994) Inhibition of endocytosis by elevated internal calcium in a synaptic terminal. Nature 370:652-655. CrossRef Medline

Wadel K, Neher E, Sakaba T (2007) The coupling between synaptic vesicles and $\mathrm{Ca}(2+)$ channels determines fast neurotransmitter release. Neuron 53:563-575. CrossRef Medline
Wu LG, Betz WJ (1996) Nerve activity but not intracellular calcium determines the time course of endocytosis at the frog neuromuscular junction. Neuron 17:769-779. CrossRef Medline

Wu LG, Borst JGG (1999) The reduced release probability of releasable vesicles during recovery from short-term synaptic depression. Neuron 23 : 821-832. CrossRef Medline

Wu LG, Ryan TA, Lagnado L (2007) Modes of vesicle retrieval at ribbon synapses, calyx-type synapses, and small central synapses. J Neurosci 27 11793-11802. CrossRef Medline

Wu W, Xu J, Wu XS, Wu LG (2005) Activity-dependent acceleration of endocytosis at a central synapse. J Neurosci 25:11676-11683. CrossRef Medline

Wu XS, Xue L, Mohan R, Paradiso K, Gillis KD, Wu LG (2007) The origin of quantal size variation: vesicular glutamate concentration plays a significant role. J Neurosci 27:3046-3056. CrossRef Medline

Wu XS, McNeil BD, Xu J, Fan J, Xue L, Melicoff E, Adachi R, Bai L, Wu LG (2009) $\mathrm{Ca}(2+)$ and calmodulin initiate all forms of endocytosis during depolarization at a nerve terminal. Nat Neurosci 12:1003-1010. CrossRef Medline

$\mathrm{Xu} \mathrm{J,} \mathrm{Wu} \mathrm{LG} \mathrm{(2005)} \mathrm{The} \mathrm{decrease} \mathrm{in} \mathrm{the} \mathrm{presynaptic} \mathrm{calcium} \mathrm{current} \mathrm{is} \mathrm{a}$ major cause of short-term depression at a calyx-type synapse. Neuron 46:633-645. CrossRef Medline

Xue J, Graham ME, Novelle AE, Sue N, Gray N, McNiven MA, Smillie KJ, Cousin MA, Robinson PJ (2011) Calcineurin selectively docks with the dynamin Ixb splice variant to regulate activity-dependent bulk endocytosis. J Biol Chem 286:30295-30303. CrossRef Medline

Xue L, Zhang Z, McNeil BD, Luo F, Wu XS, Sheng J, Shin W, Wu LG (2012) Voltage-dependent calcium channels at the plasma membrane, but not vesicular channels, couple exocytosis to endocytosis. Cell Rep 1:632-638. CrossRef Medline

Yamashita T, Hige T, Takahashi T (2005) Vesicle endocytosis requires dynamin-dependent GTP hydrolysis at a fast CNS synapse. Science 307: 124-127. CrossRef Medline

Yamashita T, Eguchi K, Saitoh N, von Gersdorff H, Takahashi T (2010) Developmental shift to a mechanism of synaptic vesicle endocytosis requiring nanodomain $\mathrm{Ca}^{2+}$. Nat Neurosci 13:838-844. CrossRef Medline

Yao J, Kwon SE, Gaffaney JD, Dunning FM, Chapman ER (2011) Uncoupling the roles of synaptotagmin I during endo- and exocytosis of synaptic vesicles. Nat Neurosci 15:243-249. CrossRef Medline

Yao L, Sakaba T (2012) Activity-dependent modulation of endocytosis by calmodulin at a large central synapse. Proc Natl Acad Sci U S A 109:291296. CrossRef Medline

Yao LH, Rao Y, Varga K, Wang CY, Xiao P, Lindau M, Gong LW (2012) Synaptotagmin 1 is necessary for the $\mathrm{Ca}^{2+}$ dependence of clathrinmediated endocytosis. J Neurosci 32:3778-3785. CrossRef Medline

Zucker RS, Regehr WG (2002) Short-term synaptic plasticity. Annu Rev Physiol 64:355-405. CrossRef Medline 